\title{
8.2 Theoretical and methodological problems of global risk analysis in social and economic spheres
}

At the turn of the millennium, under the influence of scientific, technical, sociopolitical and market changes, global social and economic transformations have accelerated significantly. The expansion and deepening of the relationship between the subjects of socioeconomic processes, which was later emphasized by modern researchers in terms of 'global society' and 'global economy', took on a global scale.

Under conditions of globalization, the uncertainty of the results of a person's actions on a society in the world has increased. The term 'global risk' has become the reflection of the magnitude of these possible results. It has been actively used recently on many international communication platforms, as well as in numerous scientific papers.

The use of the term 'global risk' is a logical extension of the tradition of business discourse to expand the range of names of the same phenomenon, process, subject, etc. in order to increase attention on a particular issue. Today, it is often possible to observe the emergence of new terms, when it becomes necessary to emphasize a certain characteristic of the already known notion. For example, this situation is observed with the terms 'international economy', 'world economy', 'global economy', etc., the emergence of which is explained by a different approach and emphasis in the study of nature, patterns, and trends in the development of relations between the participants in the system of economy in the world.

Despite the widespread use of the term 'global risk' in recent years, one has to admit that there is still confusion in the sense of its content. However, it is known that currently there is no scientific definition agreed upon by experts. There is no reliable knowledge of the essence of the subject, which is reflected by this definition. As a result, when analyzing global risk, there are a number of discussion issues that require a solution. These, first of all, should include: the division of global risk into groups, the composition of groups, the definition of each risk, the scope of the concept of 'global risk', the reference of certain risks to a specific group, etc. 
For the development of fundamental research it is important to maintain an understanding of the nature of socio-economic processes and phenomena that can take different forms during its manifestation. On this methodological basis, we shall attempt to identify and substantiate the scientific and methodological problems of the analysis of 'global risk', the significance of which has significantly grown in the era of systemic transformations of socio-economic relations. As our analysis shows, today the scientific and methodical processing of a large spectrum of problems of global risks is urgent, and, above all, it concerns the reconciliation of opinions between the theorists and practicing experts. Solving these problems will facilitate the development of ways and methods to prevent the advance of global risks, or reduce the negative consequences of their offensive.

The term 'global risk' became widespread in the mid-2000s after the World Economic Forum experts published their reports (known as the WEF Report) [404], but the study of the uncertainty of human nature, especially worldwide, disturbed scientists long before the beginning of the 21 st century.

Among these works, in our opinion, it is necessary to highlight a number of scientific works of specialists of the risk problem of the German school [405-408]. An overview of literary sources suggests a large number of scientific papers, in which scientists use the notions of 'international risk' [409], 'global risk' [410], 'worldwide risk' [411]), 'planetary risk' [412], etc., emphasizing one or another level of scale of probable dangers and their consequences in different spheres of human life. In addition, today you can observe how new terms with the given new definitions appear wave by wave. But not every new concept reflects a new phenomenon or process, often - it's just a new name that has been around for many years and is the subject of many scientific studies in different countries around the world. As a rule, the next wave of new terms appears after the dissemination of a new concept about the current stage of development of society and its main trends in the near future. In particular, the attributive categories that reflect the various aspects of the functioning and development of the system of socio-economic relations take a new form. Some issues of global risk are also discussed in the works [413-420]. 
In our opinion, scientific and methodological development of a large spectrum of problems of global risks is still insufficient today. Also, the emergence of global challenges still unknown to the world of requires new research in this direction. Existing research and development may not always be an effective tool in solving global risk analysis and developing ways and means of preventing them, or reducing the negative impact of their offensive.

The confirmation of this conclusion may be the statement of the President of WEF (Schwab, 2016) that the nature of the changes taking place is so fundamental that world history did not yet know a similar era - time of great opportunities and potential dangers. He notes, however, that national and global structures designed to mitigate the effects of possible dangers are in the best case inadequate, and in the worst case, completely absent [421].

This determines the relevance of the study, the purpose of which is to identify and justify existing problems of global risk analysis, as well as to develop proposals for possible solutions.

As our analysis shows, a number of key provisions for a qualitative analysis of global risks are controversial and require further discussion in order to reach a consensus on these issues. This, first of all, concerns the definition of the concept of "global risk", the composition of risks that form the scope of the concept of "global risk", their definition, characteristics and interconnections, as well as the construction of a system for classifying these risks.

Definition of the concept of "global risk". Among the above-mentioned issues, one of the most important is the establishment of a coherent view of experts in defining the concept of "global risk". Without a coherent approach to the definition of this concept, it is almost impossible to resolve any issue regarding the development and implementation of measures to prevent the occurrence of these risks, or reduce the negative effects of their offensive. Since there is no scientific definition of one or another concept, there is no reliable knowledge of the significance of the subject reflected by this notion. 
The state with the definition of the concept of 'global risk' can be illustrated by the example data given in Table 1.

Table 1. Concept analysis «Global risk»: definition \& context

\begin{tabular}{|c|c|c|c|}
\hline $\begin{array}{l}\text { Authors } \\
\text { Source }\end{array}$ & Definition and explanation & $\begin{array}{r}\text { Level } \\
\text { of analysis }\end{array}$ & $\begin{array}{r}\text { Field of } \\
\text { knowledge }\end{array}$ \\
\hline $\begin{array}{l}\text { Beck, U. } \\
\text { [422: p. 338] }\end{array}$ & $\begin{array}{l}\text { 'Global risk is an unpredictable and } \\
\text { impersonal force in the contemporary world, } \\
\text { triggering events to which the human response is to } \\
\text { organize on a global scale'. }\end{array}$ & $\begin{array}{l}\text { Mega } \\
\text { Level }\end{array}$ & \begin{tabular}{|c|} 
Social \\
and behavioral \\
sciences; \\
Multidisciplinar \\
y
\end{tabular} \\
\hline$\left[\begin{array}{l}\text { WEF GR } \\
\text { [423: p.11] }\end{array}\right.$ & $\begin{array}{l}\text { 'Global risks are defined as having global } \\
\text { geographic scope, cross-industry relevance, } \\
\text { uncertainty as to how and when they will occur, and } \\
\text { high levels of economic and/or social impact } \\
\text { requiring a multi stakeholder response'. }\end{array}$ & $\begin{array}{l}\text { Meso, } \\
\text { Macro, } \\
\text { Mega- } \\
\text { Micro- } \\
\text { Levels }\end{array}$ & $\begin{array}{c}\text { Social } \\
\text { and behavioral } \\
\text { sciences }\end{array}$ \\
\hline $\begin{array}{l}\text { WEF GR } \\
\text { [1: p. 100) }\end{array}$ & $\begin{array}{l}\text { 'A «global risk» is defined as an uncertain } \\
\text { event or condition that, if it occurs, can cause } \\
\text { significant negative impact for several countries or } \\
\text { industries within the next } 10 \text { years'. }\end{array}$ & $\begin{array}{l}\text { Meso, } \\
\text { Macro, } \\
\text { Mega- } \\
\text { Micro } \\
\text { Levels }\end{array}$ & $\begin{array}{c}\text { Social } \\
\text { and behavioral } \\
\text { sciences }\end{array}$ \\
\hline [424] & $\begin{array}{l}\text { 'The possibility that something bad may happen } \\
\text { which will affect all countries'. }\end{array}$ & $\begin{array}{c}\text { Macro, } \\
\text { Mega } \\
\text { Levels }\end{array}$ & $\begin{array}{l}\text { Multidisci } \\
\text { plinary }\end{array}$ \\
\hline $\begin{array}{l}\text { Mayordomo, S., } \\
\text { Peña, J. I. \& } \\
\text { Schwartz, E. S. } \\
\text { [418: p. 19) }\end{array}$ & $\begin{array}{l}\text { 'Global Risk is a measure of the overall risk } \\
\text { which is obtained from the Chicago Board Options } \\
\text { Exchange Volatility Index (VIX) and it is a } \\
\text { measure of the implied volatility of S\&P } 500 \text { index } \\
\text { options'. }\end{array}$ & \multirow[t]{2}{*}{$\begin{array}{l}\text { Micro, } \\
\text { Macro } \\
\text { Levels }\end{array}$} & \multirow[t]{2}{*}{$\begin{array}{l}\text { Business } \\
\text { and } \\
\text { Finance }\end{array}$} \\
\hline $\begin{array}{l}\text { Everett, M. } \\
\text { [419: p. 20] }\end{array}$ & $\begin{array}{l}\text { 'Global risk is a significant determinant of } \\
\text { the global flows of relatively smaller banks, less } \\
\text { capitalized banks, and banks resident in non- } \\
\text { stressed euro area countries'. }\end{array}$ & & \\
\hline
\end{tabular}


As we see, the term "global risk" is used by different authors in different contexts. Despite the generality of the name, some of them are almost completely different in nature. Even the definitions of the concept of "global risk", as outlined in the WEF Reports in different years, differ significantly. This, in our opinion, is due to the fact that the authors use terms according to the chosen approach in scientific research, subject and object of risk, the general context of work, as well as a certain understanding of the criteria for classification of risk as a scientific category.

This situation, in our opinion, is a manifestation of a well-known phenomenon when a certain term becomes popular and its scope of application expands significantly (and the term 'risk' is used quite often lately), its content usually becomes more and more uncertain.

Each author has the right to use one term or another in accordance with their understanding of the problem. However, such difference in the use of terms leads to a scientific communications break down and thus retards the development of science [420].

Let us consider this problem with the example of WEF reports, which, to a certain extent, generalize and use scientific developments in the field of global risks. Their choice was also made because of the fact that in recent years many publications devoted to global risks, as a priori use the definition of the notion 'global risk', as stated exactly in the the WEF report (2015 - 2019).

Using existing developments, we shall try to consider the existing, in our opinion, problems of analyzing the global risks, as well as to identify possible ways to eliminate them.

According to the 2019 WEF Report: A 'global risk' is an uncertain event or condition that, if it occurs, can cause significant negative impact for several countries or industries within the next 10 years [404: p.100].

Analysis of this definition allows us to draw several preliminary conclusions. First, the occurrence of risk at the country or industry level is considered. Secondly, in this definition, risk is associated only with danger or threat, which does not coincide with 
the opinion of many risk specialists. Thirdly, the source of risk is an indefinite event or condition.

This leads to the fact that the above definition from the point of view of logic is very broad. Therefore, as it will be shown later, with this approach, factors and sources of risk, the risk itself, as well as the consequences of the occurrence of risk events are included in the global risks.

In this case, in our opinion, the above definition does not cover the entire content of the concept of risk. It does not take into account all the elements, the composition and interrelation of which determines its essence.

Next, we consider this statement in more detail. At the same time, we are of the opinion that global risk is a component of the broader concept of 'risk' (without being relative to its specific object), and characterizes the features of its manifestation at the indicated level.

Most experts today express the view that risk is an attribute of the subject's activities. So Luhmann expresses the view that at risk the losses are the result of activity or inactivity [406]. Agreeing with him, well-known risk specialist Bechmann states: 'Today, dangers are derived from actions and decisions, and therefore are expressed in the form of risks. ... all the dangers we are threatened with are, in principle, generated by decisions taken or not taken' [415: p. 79].

One can also agree with the approach [425] to the definition of the concept of risk in sociology, which, in our opinion, can be used in constructing the definition of the notion 'global risk'. It is based on one of the following prerequisites: 'The risk is associated with the action and the subject who acts, exists only if there is a subject and the possibility of action. For example, a community (the Russian 'community') can only be in risk if it is recognized that the 'community' is some subject that can act' [425: pp. $62-63]$.

By activity or inaction, which may be a consequence of the emergence of global risks since the level at which they are considered are countries, or society as a whole, then we should be talking about activities at this level. This activity can be considered as aimed at ensuring their sustainable development. That is, along with the objective 
nature of the sources of risk (spontaneity of natural processes and phenomena, natural disasters, etc.), the definition of the notion 'global risk' should reflect its important feature as a subjective one.

Secondly, as it was noted in the definition of a global risk, it is associated only with danger. At the same time, today the prevailing opinion among specialists is that the result of the occurrence of a risky event is the uncertainty of the final result of the activity.

Thus, Krzakiewicz agrees that the risks are generated by decisions taken or not taken. He notes that the essence of risk is not the loss that can be experienced as a result of the decision made, but only the possibility of a deviation from the goal, for which this decision is made [413: , p. 9).

As we see, the definition of the notion 'global risk' given in the WEF Report does not take into account certain features that are inherent in the generally accepted notion of a 'risk' without reference to its particular object. Therefore, in the future, considering the phenomenon of a 'global risk', we will make an attempt to analyze it as a certain form of activity.

Before attempting to define the concept of 'global risk', which to a certain extent eliminates the shortcomings of the existing one identified by us and reflects the position of the authors on the issue under consideration, the following should be noted.

It is known that 'risk analysis' is an interdisciplinary field of knowledge which is based on the cooperation of experts in social and natural sciences. Each of these sciences has its own understanding of the subject of research, has its methodological basis.

Under these conditions, attempts have been made to provide a generalized definition of risk, which can characterize it as a general scientific concept. Such, for example, as: 'Risk is an action image in a vague uncertain environment' [426: p. 26]. The risk is 'a situational characteristic of the activity, which lies in the uncertainty of its consequences and the possibility of adverse consequences in the event of failure' [227: p. 308]. 
The development of this approach was reflected in the fact that in today's conditions of scientific knowledge development 'risk' as a general scientific concept can be defined as a category, since it reflects some common features of human activity, social life, knowledge and to a certain extent meets the criteria that allow us to attribute this or that concept to the category of categories - versatility, reflectivity, ideological value' [428: p. 70).

The above reviewed provisions, which are also consistent with our understanding of the problem, allow us to propose such a definition of 'global risk' that reflects the position of the authors in relation to the problem under consideration and may be one of the possible approaches to its solution. Global risk is a general scientific category that characterizes the uncertainty of the society's performance in relation to its development, as a result of the systematic influence of a number of interrelated objective and subjective factors on it.

Composition of global risk. In our opinion, the consequence of the very broad definition of the concept of 'global risk' used in the WEF Reports is the discussion of the composition of the risks that determine its scope, as well as their characteristics. Let's consider this question in more detail.

WEF Reports contain a number of global risks that are grouped into five groups: Economic Risks, Environmental Risks, Geopolitical Risks, Societal Risks and Technological Risks.

Unfortunately, there are no definitions of each of these groups in the WEF Reports. However, as the preliminary analysis of one of the authors of the paper [420] shows, there is at present no consistent approach to determining these risks. In addition, as you know, each of these risks manifests itself (occurs) at different hierarchical levels - the state, the economy as a whole, corporations, individual enterprises, etc. Each level is characterized by its definition of 'risk', which reflects the peculiarities of its manifestation at this level, and allows to separate it from other concepts. It is therefore desirable to provide a definition of the above risks in terms of their manifestation and application (use) at the global level. 
For example, the WEF Report [429] provides only a description (Description) of the five categories of global risks that may arise. As it can be seen from Table 2, some logical forms, similar to definitions, such as description, characteristic, explanation of the term, considered as an error from the point of view of logic, are used as definitions.

Table 2. Characteristics of 5 major categories of global risk

\begin{tabular}{|c|c|}
\hline Category & Description \\
\hline $\begin{array}{l}\text { Economic } \\
\text { Risks }\end{array}$ & $\begin{array}{l}\text { 'Risks in the economic category include fiscal and liquidity crises, failure of a } \\
\text { major financial mechanism or institution, oil-price shocks, chronic unemployment and } \\
\text { failure of physical infrastructure on which economic activity depends'. }\end{array}$ \\
\hline $\begin{array}{l}\text { Environmental } \\
\text { Risks }\end{array}$ & $\begin{array}{l}\text { 'Risks in the environmental category include both natural disasters, such as } \\
\text { earthquakes and geomagnetic storms, and man-made risks such as collapsing } \\
\text { ecosystems, freshwater shortages, nuclear accidents and failure to mitigate or adapt to } \\
\text { climate change'. }\end{array}$ \\
\hline $\begin{array}{l}\text { Geopolitical } \\
\text { Risks }\end{array}$ & $\begin{array}{l}\text { 'The geopolitical category covers the areas of politics, diplomacy, conflict, crime } \\
\text { and global governance. These risks range from terrorism, disputes over resources and } \\
\text { war to governance being undermined by corruption, organized crime and illicit trade'. }\end{array}$ \\
\hline Societal Risks & $\begin{array}{l}\text { 'The societal category captures risks related to social stability - such as severe } \\
\text { income disparities, food crises and dysfunctional cities - and public health, such as } \\
\text { pandemics, antibiotic-resistant bacteria and the rising burden of chronic disease'. }\end{array}$ \\
\hline $\begin{array}{l}\text { Technological } \\
\text { Risks }\end{array}$ & $\begin{array}{l}\text { 'The technological category covers major risks related to the growing centrality } \\
\text { of information and communication technologies to individuals, businesses and } \\
\text { governments. These include cyber attacks, infrastructure disruptions and data loss'. }\end{array}$ \\
\hline
\end{tabular}

Earlier in the study [430] was noted that in the process of constructing definitions, it is desirable to avoid a list of sources of risk, since over time these sources may change under the influence of various factors - technical, economic, social, legal, etc.

This can be illustrated with the example of Environmental Risks. A description of this risk as amended by the [491: p12] is given in Table 2. As amended by the WEF Report (2019), the definition or description of this risk is completely absent, and its components include the following global risks: Extreme weather events, Failure of climate change and adaptation, Major biodiversity loss and ecosystem collapse. In the description of these risks, which should characterize their content, are given: 
«- Extreme weather events - major property, infrastructure, and/or environmental damage as well as loss of human life caused by extreme weather events;

- Failure of climate-change mitigation and adaptation - the failure of governments and businesses to enforce or enact effective measures to mitigate climate change, protect populations and help businesses impacted by climate change to adapt;

- Major biodiversity loss and ecosystem collapse - Irreversible consequences for the environment, resulting in severely depleted resources for humankind as well as industries.» [404: p.100]

As we see, in the first and third cases, the consequences of the occurrence of risky events were used to describe the risks, in the second, the cause (source) of the risk occurrence.

The use of sources (causes) and consequences of the occurrence of risk events also occurs in the process of describing the content of risks, combined into other groups, largely for economic and social risks.

Therefore, to exclude such cases, in our opinion, to characterize individual global risks, their description (Description) and definition (Definition) should be used. There are also questions to the name of individual global risks, such as, for example, 'Illicit trade', or 'Weapons of mass destruction' and others.

The solving of this problem lies in analyzing of global risks from the causal aspect point of view. It involves consideration of any risk by taking into account the following chain - determining the factors and causes of the risk, the risk itself, as well as the consequences of the occurrence of risk events.

Let us consider the possible use of a causal-to-effect approach in the process of constructing a definition, for example, a global risk called "uncontrollable inflation", which is included in the global economic risk. Let's call it 'global inflation risk'.

One of the weighty factors that contributes to its emergence is the inefficient financial policy of the state.

The manifestation of this factor is uncontrollable inflation. The consequence of global inflation risk advance is a slowdown or even cessation of the economic development of society and individual countries. This allows us to offer the following 
definition of this risk: Global inflation risk is a component of global economic risk, which characterizes the uncertainty of the result of development activities of society and individual countries, as a result of an uncontrolled decrease in the value of money.

Discussion should also be made, as to the composition of the groups and the assignment of certain risks to a specific group of risks. In the WEF Report, all global risks are grouped into five groups: Economic Risks, Environmental Risks, Geopolitical Risks, Societal Risks, Technological Risks.

In our opinion, it is necessary to consider the validity and expediency of their expansion due to the inclusion of criminal law risks in them. It can include global risks that characterize illegal trade, massive cases of fraud and data theft, large-scale cyber attacks and the like.

It is known that the last two global risks are included in the technological risks group. However, massive cases of fraud and data theft can be the result of abuse by technical and other personnel who have access to this data, or various types of criminals. At the same time, the fact that large-scale cyber attacks is a crime in which technicaltechnological means (computer systems and computer networks) is only a weapon or the means of its implementation is not enough to include them in technological risks.

The selection of this group will allow taking into account the specificity of the analysis of global risks that are included in it, since special specific methods and measures should be applied to prevent or reduce the negative consequences of such risks occurrence.

The studies that have been carried out determine the position of the authors, which consists in the conclusion of the discussion of some basic tenets of the theory of global risk, which testifies to the complexity of the problem and its insufficient scientific elaboration. They also confirm the view that it is necessary and advisable to further deep and comprehensive research on this issue. Further research on the issues addressed should be aimed at: Definition of the concepts of each group into which global risks are divided; and also definition, but not the description of each of global risks entering into these groups; determination of the necessity and expediency of clarifying the composition of the groups into which global risks are divided, as well as 
the assignment of certain risks to these groups. It is also advisable to construct a system of classification of global risks, which will allow respondents to choose from them, in their opinion, the most significant and probable risks.

Solving the problems considered will create conditions for developing effective methods and measures to prevent or reduce the negative consequences of the occurrence of these risks, which will mitigate the negative consequences of the occurrence of global risks on all aspects of human life. 